\title{
Affective Commitment: A Comparative Study across Variant Units and Ranks of the National Police Service, Kenya
}

\author{
Charles Mbugua \\ PhD Candidate \\ Organizational Leadership \\ Pan Africa Christian University \\ Kenya
}

\begin{abstract}
Many researches on organizational leadership of security services lack attention on organizational commitment, and by extension on its key dimension: affective commitment. Similarly studies on the National Police Service of Kenya have majorly focused on corruption, ignoring the critical place of affective commitment: the construct which reflectsthe extent to which employees are emotionally attached to the organization. This study was then carried out to identify the perception levels of affective commitment across the units and ranks of National Police Service, Kenya. Analysis revealed an overall low level of affective commitment (mean=2.806) with the middle rank range of sergeant to senior sergeant having the highest level (mean= 2.843). From the findings, the service then needs to adopt an organizational leadership practice that focuses on enhancing affective commitment across its units and ranks, if officers are to offer quality service in line with the envisaged vision.
\end{abstract}

Keywords: affective commitment, social exchanges, organizational leadership.

\section{1: Introduction}

\subsection{Background of the study}

Organizational commitment (OC) is a multidimensional construct with the three dimensions; affective, continuance, and normative commitment, having contextual relations between the organization and employee's behavioral and attitudinal perspectives (Xiu \& Pyne, 2018). The affective commitment (AC) perspectives include; emotional desire to remain a member of the organization, a strong identification with the organizational processes, and a strong sense of organizational belongingness (Allen and Meyer, 1990). Employees with high levels of AC have attitudes, perceptions and hence behaviors characterized by having the best interest of the organization in their mindsets and openness to access social resources from other employees for better performance (van Gelderen \& Bik, 2016).

Continuance commitment (CC) is a comparative perspective where an employee weighs the gains between leaving and staying premised on what the employee would lose in leaving against what to gain on leaving (Woon, Tan, \& Nasurdin, 2017). Among the predictors of CC include those related to; employee, tasks, nature of organization, and the external ecosystem (Woon et al., 2017). Normative commitment (NC) reflects the moral obligation of an employee to remain a member of the organization as reciprocity to the social resources provided by the organization. Among these is the moral obligation to fellow employees a factor of one's organizational socialization, and hence an outcome of organizational processes (Allen and Meyer, 1990).

Affective commitment is viewed as the root construct of $\mathrm{OC}$ from both the historical and theoretical perspectives, and hence is the core essence of OC (Mercurio, 2015). By extension AC has shown higher correlations, from empirical evidence, with a matrix of behavioral variables, with CC and NC showing lower values (Solinger et al., 2008). It has also a predictive effect on organizational behaviors such as; turnover, absenteeism, and organizational citizenship behaviors (OCB). During organizational change, a frequent organizational process in the current global complexities, high AC plays a critical role by making employees; positive, flexible and agile towards change. To the contrary, low AC impedes organizational change through resistance to change owing to uncertainties, ambiguities, and anxieties with consequent low emotional attachment and support to change (Cummings \& Worley, 2014).

Police officers with a high AC have self-efficacy in seeking for social resources besides the habit of proactively reaching out to those with more experience and knowledge in order to learn from them. They also exhibit the behavior of learning from their own weaknesses and failures. Fluid social resources exchanges are an indicator of organizations with the critical leadership practice of high quality social exchange, a precedent for high AC (Atitumpong \& Badir, 2018). 
Through high quality social exchanges (SE) there is a bidirectional organizational leadership current between; leaders and followers, supervisors and juniors, and in police services, this results in high quality services (Chen et al., 2014). The nature of policing is not only one of the most unique public services, but by extension one fraught with; dangers that are a threat to life, stress that is traumatizing, suspicion, and emerging complexities (Duran et al., 2018; Waller et al., 2017). Loose coupling, a situation of mismatch between the demand and supply of resources including denial of relevant data and information, (Domingues \& Machado, 2017; Knight, 2017), is a major cause of traumatic stress in policing. By extension the hierarchical nature of police organizations characterized by commands makes police services get referred to as greedy organizations since there is a demand for total sacrifice and loyalty (Coser, 1974). This organizational nature catalyzes relational conflicts and consequently lowers the quality of SE. Some of the operational encounters and relational practices have resulted in officers committing suicide, an indicator of underlying unresolved intrapersonal and interpersonal conflicts (Chae \& Boyle, 2013; Donner, Maskaly, \& Fridell 2016) including trauma.

Employees with high AC irrespective of their ranks and positions in police services and other organizations respectively, readily volunteer their human capital towards helping others, an indicator of their OCB. Such extra-role behaviors as outcomes of high AC include; mentoring, coaching, training, and leading, with resultant reciprocity from the recipients which adds to further AC across the organization (Gupta \& Sharma, 2018).

On the other hand, officers who have the perception that they are unfairly treated exhibit their dissatisfaction through organizationally destructive behavior including absenteeism with ultimate decision to leave owing to low AC (Donner et al., 2016). Among indicators of unfair mistreatment include those documented by (Barn, 2017; IPOA, 2017) detailing mistreatment of junior NPS officers by their seniors. This could affect the AC of junior officers negatively with resultant; low AC, attitudes, and behaviors, detrimental to the values, mission, and vision of the organization.

In the (IPOA, 2016) report, among the complaints pointing at NPS malpractices included; inaction, misconduct, and assault, indicators of a total and unethical departure from the NPS' aphorism of 'Service to all with Trust and Justice'. By extension these are behaviors and attitudes that reflect lack of AC, a departure from the wordings of the NPS aphorism.

In an era of global turbulences occasioned by emerging complex threats such as; terrorism, cyber fraud, criminal gangs, and transnational crimes Mansour (2017), high levels of AC are critical in regard to the vital role of police services to national safety and security. Global complexities of ageing workforces coupled with generational differences that present diversities across ranks and organizational groups abound (Jain \& Duggal, 2018). If not well managed the resultant diverse; attitudes, stereotypes, perceptions, and beliefs can affect AC negatively.

Being the most important driver of OC (Mercurio, 2015), affective commitment becomes a critical buffer in making organizations remain buoyant against the turbulences of the ever changing organizational landscapes. One core complexity facing NPS, is caused by the on-going NPS reforms, that have seen the introduction of distinct units namely: Administration Police Service (APS), Directorate of Criminal Investigation (DCI), Kenya Police Service (KPS) and Internal Affairs Unit (IAU), an organizational change context that has seen resistance through perceptions of exclusion and particularly by junior officers (TI, 2016).

\subsection{Problem statement}

For a long time there has been a perception among the public that the police service in Kenya, hitherto referred to as the Kenya Police Force (KPF), has been more of a liability than a vital safety and security service organization. In line with the National Taskforce on Police Reforms Report (Ransley, 2009), the KPF was seen to abuse human rights through acts of; extortion, extrajudicial killings, and being partial through service to politicians, a threat to both safety and security.

Despite the NPS aphorism in which trust and justice are to be espoused through the behaviors and processes of the NPS, officers have been involved in unethical, criminal, and immoral behaviors against the public. Similarly other negative work behaviors within the NPS characterized by; mistrust among officers, mistreatment of junior officers, suicidal and homicidal behaviors, incompetence, and criminal activities such as rape and theft, have been documented in various studies (Hope, 2018; IPOA, 2017).

An understanding of the context and concept of AC by NPS leadership across the different NPS units and ranks then becomes a critical organizational leadership practice. This requires evidence-based approaches, a practice that has been lacking across police organizations globally (Lum \& Coper, 2017), in spite of such approaches being known to deliver effective service delivery across police services (Weisburd \& Neyroud, 2014).

\subsection{Research objectives}

The overall objective was to identify if there is a difference in the affective commitment scores across NPS ranks and units.

The specific objectives are: 
i. To determine the affective commitment levels for APS, DCI, and KPS in the NPS

ii. To establish the affective commitment levels for various NPS ranks

iii.To determine the differences in the affective commitment levels across NPS ranks

\section{2: Review of Literature}

\subsection{Affective Commitment}

In an article titled "The High Cost of Federal Workforce Depression," it was noted that there were low levels of morale across the U.S Secret Service employees and lack of emotional attachment to the organization (Risher, 2014): indicating. low AC, in the organization. This is supported by the findings that emotional attachment to an organization must be based on an enacted behavior within the organization (Alvino, 2014). Linking this to security services, whose work is characterized by atypical working hours, destructive relationships, and working under stressful conditions (Benitez, Medina, \& Munduate, 2018), justifies why emotional attachment, a key antecedent of AC, is core from a leadership lens.

Research findings from a study carried out by (van Gelderen \& Bik, 2016) revealed that the support by supervisors, which represents enacted behavior, positively influenced employee's OCB. By extension it showed that AC was positively related to the employee behavior of seeking for social resources from colleagues. Both OCB and the seeking for social resources are behaviors emanating from either organizational processes or the behavior of the leadership. It is this reciprocity exemplified by behaviors between leaders and followers that social exchanges are premised on.

In the research on OC, (Kumari \& Priya, 2017) found out that there is a statistically significant difference between the OC of top, middle, and lower level managers, $(\mathrm{F}=17.593, \mathrm{p}=0.000)$, with the means and standard deviations $(\mathrm{SD})$ of the aforementioned three levels being; (mean=3.8409, $\mathrm{SD}=0.55886$; mean=3.5910, $\mathrm{SD}=0.62009$; mean=3.4252, $\mathrm{SD}=0.65717$ ) respectively. In the same study the $\mathrm{OC}$ dimension with the highest mean in the public sector organization sample was $\mathrm{AC}$ (mean=3.8250, $\mathrm{SD}=.80598)$, followed by $\mathrm{NC}$ (mean=3.7489, $\mathrm{SD}=.74230)$ and $\mathrm{CC}(\mathrm{mean}=3.5478$, $\mathrm{SD}=$.69259). This is line with (Yousaf et al., 2011 in Kumari \& Priya, 2017) assertions that the dimension with the highest mean should be AC, an assertion further supportedby the findings of AC of police officers in India (Singh, 2015): with $\mathrm{AC}$ (mean= 4.133) for the highest hierarchy, officers, being higher than for the other two respective levels of; subinspectors (mean $=3.971)$ and constables (mean= 3.798).

The OC research study on the Teachers Service Commission (TSC) of Kenya (Masese, 2017), returned an AC (mean=3.65, $\mathrm{SD}=1.52)$ which the researcher defined as a moderate mean, with the sample being a homogenous group of TSC employees, while the AC for Que bec, Canada public sector was (mean=3.64, SD=0.67) (ST-Hilaire \& Robertie, 2018).

Research study focusing on organizational commitment, rank and job satisfaction in the General Service Unit (GSU) of the KPS showed that CC had the highest mean (mean=3.074), NC (mean=2.9), and AC (mean=2.618), with the recommendations calling for policies focusing on how to improve commitment (Mwai, 2014). In the recommendations there is no mention of the critical role of organizational leadership towards enhancing the organizational commitment of the NPS. By extension, this research only focused on one of the three main units of the NPS and hence was not generalizable within the entire service, which has distinct NPS units of; KPS, APS, and DCI.

Following the promulgation of the Constitution of Kenya, 2010 (CoK, 2010),enactment of; National Police Service Act 2011 and the National Police Service Commission Act 2011, a number of far-reaching organizational changes were envisaged and initiated, an on-going process to-date. Part of this was premised on documented past injustices meted on the public through the then KPF, as captured through the National Taskforce on Police Reforms (Ransley, 2009).

In spite of the many research studies focusing on the reform agenda of the NPS (Hope, 2018; IPOA, 2017; Karanja, 2013; Ojienda, 2013; Ondoro, 2015), it is evident that there has been no focus on the role of AC towards having; positive attitudes on change, OCB, and role of sharing social capital through leadership processes such as mentoring. A critical focal organizational leadership concept and context then has been lacking in the many diagnostic approaches on the dilemmas facing NPS and its predecessor, KPF. Organizational leadership has an inextricable linkage with the nature of the organizational structure, with the police having a hierarchical nature as well as differentiations in power and function. The leadership then permeates across hierarchies, processes, systems, diversities, structures, and emerging dynamics: for it to be effective, it must then factor in all these diverse contexts and complexities.

\subsection{Theoretical Framework}

\subsubsection{Social exchange theory}

Blau's (1964) social exchange theory plays a central role in the understanding of organizational socialization processes that are a hallmark of effective organizational leadership, involving intrapersonal, interpersonal, group and organizational relational practices. The relationship between an employee and the organization (Ashikali \& Groeneveld, 2015) is critical 
in enhancing AC. This is through the relational perceptions the employee develops about; supervisors, leaders, groups, teams, and organizational processes. It is premised on particular types and levels of SE which serve as motivators towards an employee's attitudes and behaviors (Keskes et al., 2018).

The desire and willingness of an employee to exert discretionary effort towards achieving exceptional individual performance (Gupta \& Sharma, 2018) is a function of one's motivation and is a factor of three components namely; direction, intensity, and persistence (Ivancevich et al., 2014). Extra-role behaviors include OCB an indicator of identification of employees with the organizational values, processes, and leadership (Gupta \& Sharma, 2018; Obedgiu et al., 2017).

When employees perceive that their treatment and engagement by the organization resonates with the laid down organizational values and that they are perceived as critical players in the organizations, they feel duty bound to reciprocate. This reciprocity emanates from perceived and experienced SE (Antony et al., 2018), through actions of organizational support such as; training, development, motivation, and promotion (Pauget \& Chauvel, 2017).

Organizational processes are one of the mirrors through which employees view the organization from; micro, meso, and macro-levels, with correspondent effects on the perceptions and attitudes they consequently develop. One critical organizational process is decision-making through which organizational resources are shared and therefore serves as a SE platform. Skewed decision-making characterized by organizational injustice where some employees are excluded from organizational resources and processes, results in organizational cynicism (Suifan et al., 2017).

This catalyzes negative relational attitudes and behaviors characterized by emotional detachment from organizational values and vision as seen in negative stereotypes (Ivancevich et al., 2014). Low self-esteem and self-worth, coupled with anger against perceived immoral acts by leaders, form part of the mindset of the employee. Correspondent low AC crops up and is evidenced by; mistrust of a matrix of organizational elements, withdrawal of employee's resources such as withholding sharing of knowledge, inaction, and finally turnover (Sprinkle \& Urick, 2018). In the NPS this has been observed in relation to negative work behaviors including brutality (Hope, 2018;IPOA, 2017); that are indicators of low AC. This negative SE is reciprocity to perceived organizational injustice with consequent negative effect on affective commitment.

\section{3: Research methodology}

The research study used a quantitative approach with researcher objectivity focusing on measuring affective commitment and analyzing the dataset using descriptive analysis. A quantitative design was used in order to generate deductive reasoning with consequent generation of predictions on affective commitment. Since the research was focusing on two dichotomous components of the NPS namely NPS ranks and correspondent levels of affective commitment, a correlational analysis method was applied. This involved comparing the affective commitment scores for different rank categories.

The population of interest was the range of NPS officers between the hierarchies of constable and senior superintendent grouped into three ranges namely; constable to corporal, sergeant to senior sergeant, and inspector to senior superintendent. These categories resonate respectively with the following leadership levels; low, middle, and upper levels. It involved a case study of the NPS focusing on the three units of NPS namely; APS, DCI, and KPS. The sampling technique used was complex stratified sampling of geographical NPS sub-strata from a legislative geographical stratum. Purposeful sampling of NPS groups within each sub-strata was undertaken. The purposeful sampling was applied to avoid any bias in sampling. The sample size had a total of 148 respondents representing each of the NPS units and the three rank ranges.

Affective commitment was measured using an adaptation of Allen and Meyer's Affective Commitment Scale (Meyer \& Allen, 1990) using a 5-point Likert scale questionnaire consisting of eight items. The scores ranged as follows; strongly agree (5), agree (4), neither agree nor disagree (3), disagree (2), and strongly disagree (1).

\section{4: Data analysis and interpretation}

Cronbach's alpha $(\alpha)$ was used in this study to measure the internal consistency of the items of the affective commitment scale which gave $\alpha$ value of 0.786 . This value is within the range of 0.7 to 1 , which depicts a high and therefore acceptable reliability (Heale \& Twycross, 2015).

Descriptive statistics were analyzed using SPSS version 23.0 and included; mean, frequency, percentages, and standard deviation (SD). Of the 148 respondents only 107 returned duly filled questionnaires representing a $72.3 \%$ completion rate which is defined as excellent for onward data analysis. The skewness was 0.044 while the Kurtosis statistic for the data was 0.494 , depicting normal distribution of the data since the skewness lies within the acceptable range of -1 to 1 , while kurtosis is near a value of zero when compared to the acceptable range of from -3 to +3 . 
Table 2.1 shows the demographic characteristics of the NPS respondents: NPS unit, rank ranges, and age groups.

Tables

Table 2.1: Demographic Characteristics of NPS Respondents

\begin{tabular}{llcc}
\hline & Characteristic & Frequency & Percentage \\
\hline NPS & APS & 50 & 46.7 \\
& DCI & 15 & 14 \\
\hline \multirow{4}{*}{ Rank } & KPS & 42 & 39.3 \\
Range & Total & 107 & 100 \\
& Constable-Corporal & 42 & 39.3 \\
& Sergeant -Senior Sergeant & 28 & 26.1 \\
& Inspector -Senior & 37 & 34.6 \\
& Superintendent & & \\
Age & Total & 107 & 100 \\
& $25-29$ & 10 & 9.3 \\
& $30-34$ & 28 & 26.2 \\
& $35-39$ & 26 & 24.3 \\
& $40-44$ & 18 & 16.8 \\
& $45-49$ & 10 & 9.3 \\
& $50-54$ & 13 & 12.1 \\
& $55-59$ & 2 & 1.9 \\
& Total & 107 & 100
\end{tabular}

Table 2.2 shows that the means for different NPS ranks are as follows; Constable -Corporal (mean=2.76, $\mathrm{SD}=0.4404)$, Sergeant-Senior Sergeant (mean=2.84, SD=0.6694), and Inspector - Senior Superintendent (mean=2.81, $\mathrm{SD}=0.5428)$. The means indicate that the rank range, Sergeant-Senior Sergeant, a middle-management level, has the highest affective commitment score, followed by Inspector -Senior Superintendent, a top-management level. The Inspector -Senior Superintendent is at a higher hierarchy and hence leadership level than Sergeant-Senior Sergeant. In line with (Kumari \& Priya, 2018), a higher hierarchical level should be having a higher affective commitment score than the rest, as a critical leadership posture core in enhancing the AC of lower levels through the observed individual and relational behaviors and attitudes of the senior levels. 
Table 2.2. Means and Standard Deviations across the ranks of variant NPS units

\begin{tabular}{lllll}
\hline Rank & NPS Group & Mean & Std, Dev & N \\
\hline Constable -Corporal & DCI & 2.7 & 0.420193 & 5 \\
& APS & 2.7625 & 0.523934 & 20 \\
& KPS & 2.772059 & 0.354203 & 17 \\
Sergeant -Senior Sergeant & NPS & 2.758929 & 0.440337 & 42 \\
& DCI & 2.775 & 0.703784 & 5 \\
& APS & 2.882813 & 0.498711 & 16 \\
Inspector -Senior Superintendentent & KPS & 2.803571 & 0.794692 & 7 \\
& NPS & 2.84375 & 0.669406 & 28 \\
& DCI & 2.775 & 0.504445 & 5 \\
& APS & 2.758929 & 0.456668 & 14 \\
NPS & KPS & 2.902778 & 0.650789 & 18 \\
& NPS & 2.831081 & 0.669406 & 37 \\
& DCI & 2.75 & 0.504445 & 15 \\
& APS & 2.80 & 0.456668 & 50 \\
& KPS & 2.83 & 0.650789 & 42 \\
& AC & 2.81 & 0.542757 & 107 \\
\hline
\end{tabular}

\section{5: Summary of findings, conclusions and recommendations}

\subsection{Findings}

The NPS mean score of affective commitment is 2.81 out of a possible maximum value of 5.00. In comparison to the mean of employees of Teachers Service Commission's affective commitment of 3.65, which was described as moderate, the one of NPS at 2.81 signifies a low organizational affective commitment.

Across the NPS units the means of; DCI, APS, and KPS are 2.75, 2.80, and 2.83 respectively, implying that even within the individual units having specific NPS safety and security mandates, the affective commitment is equally low. This has serious implications in indicating the threat posed by lack of relevant organizational leadership practices to the emotional attachment of the officers to their respective NPS units and sub-units.

The study findings further show that within the management and hence leadership levels categorized under the NPS ranks category, the rank range with the highest score of affective commitment is Sergeant to Senior Sergeant, a middle-level hierarchy. The top level rank range of Inspector to Senior Superintendent follows, with the Constable to Corporal having the lowest perception scores. Under the rank categories of different NPS units, that of Inspector to Senior Superintendent of the KPS has the highest score level (mean=2.90, $\mathrm{SD}=0.6508)$, followed closely by the Sergeant to Senior Sergeant category of APS with (mean $=2.88, \mathrm{SD}=0.7945)$.

The higher score by a middle-level rank range, Sergeant to Senior Sergeant of the APS, negates the assertions by (Mercurio, 2015; Singh, 2015), that in a hierarchical organization higher hierarchies have AC levels higher than lower levels. The research study on OC of the Indian police across different hierarchies, noted that the highest hierarchy also had highest AC levels (Singh, 2015), a different status from this study of NPS. This then shows an organizational leadership problem at the higher levels in the NPS. Each of the DCI rank categories has a mean below 2.80 and although the overall NPS and group means are low, the scores of DCI depict a trend that defies the empirically observed trends where the affective commitment of top-level leaders should be higher than that of middle-level, whose score should in turn be higher than that of the low-level leaders (Mercurio, 2015). This evidence-based assertion is only observed in the KPS with the overall NPS trends across ranks failing the test.

From the assertion by (Mousa \& Alas, 2016) that affective commitment has the highest score among the three dimensions of organizational commitment, the mean score of 2.81 of the NPS coupled with the low means across ranks and NPS groups, implies an overall low organizational commitment. This is in spite of the critical role of the NPS in line with the mandates of each of its specialized services, and the organizational training across ranks and groups. 
Viewed from a mean score of 2.68 of the GSU in an empirical study (Mwai, 2014), and factoring in the space of reforms undertaken in the last eight years, mirrored against the ever evolving turbulence within the tactical, operational and strategic environments, there is a justified urgency to rethink organizational leadership practices in the NPS. Low affective commitment across the hierarchies of the NPS as well as across the three units depicts an entire organizational leadership gap, with a need for an organizational diagnosis. Of utmost significance is the profiling of the role of effective organizational leadership on enhancing affective commitment as an antecedent to quality services to the internal customers of the NPS, the police officers themselves.

This creates an attitude of respect to the employee from the; organization, organizational leadership, and team members. By extension the behaviors of NPS officers with high affective commitment which include extra-role behavior to the external customers, the public, serves a critical relational role. It delivers trust within the public increasing opportunities of partnership and more so in an ever emerging complex ecosystem that calls for collaborative leadership. In its absence will be propagation of destructive police behavior with consequent conflicts with the very public that police should be serving. This further increases negative perception by the public, alienating the NPS from the much needed high quality relational exchanges with the public.

High quality social exchanges should purposefully permeate across all levels of leadership with an intent meant to influence the attitudes of top, middle and low - level leaders and followers. Such social exchanges should be rooted in the diverse relational practices at; personal-level, dyadic-level, team-levels, task-levels, and organizational-levels. Emphatic leadership practice within these relations is core towards availing relevant social resources and fairness to all officers. Such practices should allow for free and authentic participation in critical decision-making processes affecting officers, such as; training, task-roles, promotions, work environment, mentoring, and transfers.

Perceptions of organizational injustice generated through unfair sharing of organizational resources is an antecedent of low affective commitment. Employees have expectations of organizational justice from the organizations that they serve, and the nature of organizational justice consequently affects the attitudes and behaviors of employees to organizations (Armagan \& Erzen, 2015). Leaders who ignore their leadership role in regard to creating positive SE attitudes, knowledge, perceptions and behaviors relating to themselves, followers and the organization, run the risk of creating organizational cynicism. The resultant; mistrust, dissatisfaction with outputs from processes and procedures, and negative evaluation of leadership and organization, is destructive. These are negative organizational behaviors, indicators of low affective commitment, which affect both intrapersonal and interpersonal relations.

Among the intrapersonal conflicts include those whose symptoms are negative effects on personal health (Robbins, Ford, \& Tetrick, 2012), including mental health (Eib, 2015), absenteeism, resignation, and suicide (Chae \& Boyle, 2013). On the other hand, interpersonal conflicts might result in negative emotions resulting in low self-control and homicide against colleague police officers (Benitez et al., 2018; Donor et al., 2015). Such cases including suicidal and homicidal tendencies have been observed and documented in the National Police Service of Kenya.

Low quality social exchanges below the expectations of an employee further add to the perceptions of organizational injustice with a further effect on affective commitment. This is through perceptions of unpredictability of the organization in future engagements with consequent emotional detachment (Eib, 2015). Leadership that creates positive attitudes, knowledge and perceptions about itself and the organization, through positive social exchanges that reflect organizational justice catalyzes employee trust. Correspondent attitudes, knowledge and behaviors deliver high affective commitment.

\subsection{Conclusion}

The organizational changes in the NPS have seen the new structure having the following distinct strategic; roles and leadership levels; DIG-KPS in charge of public safety and security, DIG- APS in charge of protective and border security, and Director-DCI in charge of criminal investigations. The three are under the command and leadership of the Inspector General of the National Police Service.

For the NPS to achieve its vision and mission, each of the three NPS strategic units; KPS, APS, and DCI, should deliver their mandate optimally. To achieve this, the officers across each unit and therefore across ranks, should have high affective and hence organizational commitment levels. Failure to adapt and integrate effective leadership; practices and styles core towards catalyzing high affective commitment becomes a multi-pronged liability. This liability is not only to one specific unit, but also to other units, ranks, and individual officers, and at the national level, to national safety and security. In line with Kenya's threats from; criminal gangs, transnational crimes, violent extremism and Kenya's inescapable role in the global war on terror, lack of affective commitment further endangers both regional and global security. 
Harmonizing organizational leadership models across NPS is then a critical adaptive leadership practice needed to achieve high affective commitment in an operational environment characterized by need for complex intra-organizational and inter-organizational social exchanges. A fundamental organizational leadership practice will then require an in-depth understanding of the models needed towards enhancing employees' perception of the organization from the following nexus points; job characteristics, task roles, and the organizational climate. .

Healthy social exchanges across each of these facets will be one hallmark of effective leadership within the NPS and should be practiced across the entire structure across ranks and the units of the NPS.

Besides the relational social exchanges between supervisors and their juniors, is the adaptive need for an innovative high quality SE leadership model across the NPS.

\subsection{Recommendations}

I recommend the institutionalization of use of evidence-based approaches towards measuring affective commitment within the NPS from different contexts of its organizational leadership practices.

I also recommend an organizational leadership model that enhances collaborative leadership practices that cultivate affective commitment across the NPS units.

I recommend the institutionalization of organizational leadership practices that focus on affective commitment across the ranks and cadres of the entire NPS.

I further recommend a diagnosis of the organizational learning culture of the NPS from the lens of organizational leadership focusing on organizational commitment. This should encompass all the different training and capacity building spaces of the NPS right from the basic training schools to those offering further general and specialized

strategic leadership and learning experiences.

The NPS should assess its leadership practices in regard to affective commitment with effective leadership then being measured through the scores of the various dimensions of organizational commitment.

Finally there is need for the NPS to have on board a dynamic organizational leadership curriculum that is evidence-based and focused on delivering a platform of effective leadership practices informed by current and futuristic complexities of policing.

\section{References}

Allen, N. J., \& Meyer, J. P. (1990). The measurement and antecedents of affective, continuance and normative commitment to the organization. Journal of Occupational Psychology, 63(1), 1-18.

Alvino, L. (2014, 29 September). Engage your employees or lose billions. Forbes Magazine. Retrieved from http://www.forbes.com/sites/womensmedia/2014/09/29/engage-your- employees-or-lose-billions.

Antony, J., Rodgers, B., Coull, I., \& Sunder, V. M. (2018). Lean Six Sigma in policing services: A case study from an organisational learning perspective. International Journal of Productivity and Performance Management, 67(5), 935-940, https://doi.org/10.1108/IJPPM-07-2017-0173.

Armagan, Y., \& Erzen, E. (2015).The effect of leadership on organizational justice. Leadership and Organizational Outcomes, 239-254.doi 10.1007/978-3-319-14908-0_15.

Ashikali, T., \& Groeneveld, S. (2015). Diversity management for all? An empirical analysis of diversity management outcomes across groups. Personnel Review, 44(5), 757-780, https://doi.org/10.1108/PR-10-2014-0216.

Atitumpong, A., \& Badir, Y. F. (2018). Leader-member exchange, learning orientation and innovative work behavior. Journal of Workplace Learning, 30(1), 32-47, https://doi.org/10.1108/JWL-01-2017-0005.

Benitez, M., Medina, F. J., \& Munduate, L. (2018). Buffering relationship conflict consequences in teams working in real organizations. International Journal of Conflict Management, 29(2), 279-297.

Blau, P. M. (1964). Exchange and Power in Social Life. John Wiley \& Sons, New York, NY.

Chae, M. H., \& Boyle, D. J. (2013). Police suicide: prevalence, risk, and protective factors. Policing: An International Journal of Police Strategies \& Management, 36(1), 91-118, https://doi.org/10.1108/13639511311302498

Chen, C. M., Lee, H. T., Chen, S. H., \& Tsai, T. H. (2014). The police service quality in rural Taiwan: A comparative analysis of perceptions and satisfaction between police staff and citizens. Policing: An International Journal of Police Strategies \& Management, 37(3), 521-542.

Coser, L. A. (1974). Greedy Institutions: Patterns of Undivided Commitment. Free Press, New York, NY.

Cummings, T., \& Worley, C. (2014). Organization development and change. Stamford, CT: Cengage Learning. 42(2), 81-91. 
Domingues, I. P., \& Machado, J. C. (2017). The loosely coupled factors of organizational stress in police forces. Policing: An International Journal, 40(4), 657-671. doi.org/10.1108/PIJPSM-08-2016-0128.

Donner, C. M., \& Jennings, W. G. (2014). Low self-control and police deviance: applying Gottfredson and Hirschi's general theory to officer misconduct. Police Quarterly, 17(3), 203-225.

Donner, C. M., Maskaly, J., \& Fridell, L. A. (2016). Social bonds and police misconduct: an examination of social control theory and its relationship to workplace deviance among police supervisors. Policing: An International Journal of Police Strategies \&Management, 39(2), 416-431.

Duran, F., Woodhams, J., \& Bishopp, D. (2018). An interview study of the experiences of firefighters in regard to psychological contract and stressors. Employee Responsibility Rights Journal, https://doi.org/10.1007/s10672$018-9314-\mathrm{z}$

Eib, C. (2015). Processes of Organizational Justice: Insights into the perception and enactment of justice. Holmbergs, Malmö, Sweden.

Gupta, N., \& Sharma, V. (2016). Exploring employee engagement - a way to better business performance. Global Business Review, 17(3), 45S-63S.

Hair J., Anderson, R., Tatham, R., \& Black, W. (1998). Multivariate data analysis with Readings. Prentice Hall, New Jersey.

Heale, R., \& Twycross, A. (2015). Validity and reliability in quantitative studies. Evidence Based Nursing, 18(3), 66 67. doi: 10.1136/eb-2015-102129.

Independent Policing Oversight Authority (IPOA), (2017). Monitoring Report on Police Conduct during Public Protests and Gatherings: A Focus on the Anti-IEBC Demonstrations (April - June 2016).

Independent Policing Oversight Authority (IPOA), (2017). Performance Report July - December, 2016.

Ivancevich, J. M., Konopaske, R., \& Matteson. M. T. (2014). Organizational Behavior \&Management (10th ed.). McGraw-Hill.

Jain, P., \& Duggal, T. (2018). Transformational leadership, organizational commitment, emotional intelligence, and job autonomy: Empirical analysis on the moderating and mediating variables. Management Research Review, https://doi.org/10.1108/MRR-01-2018-0029.

Keskes, I., Sallan, J. M., Simo, P., \& Fernandez, V. (2018). Transformational leadership and organizational commitment: Mediating role of leader-member exchange. Journal of Management Development, 37(3), 271-284, https://doi.org/10.1108/JMD-04-2017-0132.

Knight, G. M. (2017). Impact of loose coupling on police effectiveness. Australian \& New Zealand Journal of Criminology, 50(2), 269-281, doi.org/10.1177/0004865815620704.

Kumari, P., \& Priya, B. (2017). Organizational commitment: A comparative study of public and private sector bank managers. International Journal of Business and Management Invention, 6(1), 38-47.

Lum, C., \& Koper, C. S. (2017). Evidence-Based Policing: Translating Research Into Practice. Oxford Press, Oxford.

Mansour, E. (2017). The potential role of university libraries' manpower, collections, services, facilities and activities in promoting national security in times of crises in Upper Egypt.Library Management, 38(4/5), 182-202, https://doi.org/10.1108/LM-08-2016-0063.

Mercurio, Z. A. (2015). Affective commitment as a core essence of organizational commitment: An integrative literature review. Human Resource Development Review, 1-26. DOI: 10.1177/1534484315603612.

Obedgiu, V., Bagire, V., \& Mafabi, S. (2017).Examination of organizational commitment and organizational citizenship behaviour among local government civil servants in Uganda. Journal of Management Development, 36(10), 1304-1316, doi.org/10.1108/JMD- 12- 2016-0279.

Pauget, B., \& Chauvel, D. (2017). Intergenerational learning and memory. The Learning Organization, https://doi.org/10.1108/TLO-11-2017-0113.

Ransley, P. (2009). National Task Force on Police Reforms. Republic of Kenya.

Risher, H. (2014). The high cost of federal workplace depression. Government Executive. Retrieved from http://www.govexec.com/management/2014/10/secret-service-woes- showhigh-cost-poor-morale/96305/

Robbins, J. M., Ford, M. T., \& Tetrick, L. E. (2012). Perceived unfairness and employee health: A meta-analytic integration. Journal of Applied Psychology, 97(2), 235-272.

Singh, A. P. (2015). A study on organizational commitment of police employees. The International Journal of Indian Psychology, 3(1).

Solinger, O. N., van Olffen, W., \& Roe, R. A. (2008). Beyond the three-component model of organizational commitment. Journal of Applied Psychology, 93, 70-83.

Sprinkle, T. A., \& Urick, M. J. (2018). Three generational issues in organizational learning: Knowledge management, perspectives on training and "low-stakes" development. The Learning Organization, 25(2), 102-112, https://doi.org/10.1108/TLO-02-2017-0021. 
Suifan, T. S., Diab, H., \& Abdallah, A. B. (2017). Does organizational justice affect turnover-intention in a developing country? The mediating role of job satisfaction and organizational commitment. Journal of Management Development, 36(9), 1137-1148, https://doi.org/10.1108/JMD-02-2017-0048.

Tankebe, J. (2010). Identifying the correlates of police organizational commitment in Ghana. Police Quarterly, 13(1) 739, doi: 10.1177/1098611109357324.

Tavakol, M., \& Dennick, R. (2011). Making sense of Cronbach's alpha. International Journal of Medical Education, 2, 53-55.

Transparency International Kenya. (2016). Kenya Police Service Satisfaction Survey and Needs Analysis Report, 2016: A Focus on Kisumu and Nairobi Counties. Retrieved from https://tikenya.org/wp-content/uploads/2018/01/Report-of-the-Review-of-the-Anti-Corruption-Provisions-inthe-the-National-Police-Services-Basic-Training-Syllabus-and- Regulations-2011.pdf.

van Gelderen, B. R., \& Bik, L. W. (2016). Affective organizational commitment, work engagement and service performance among police officers. Policing: An International Journal of Police Strategies \& Management, 39(1), 206-221, https://doi.org/10.1108/PIJPSM-10-2015-0123.

Waller, L., Millar, C., \& Culpin, V. (2017). Guest editorial. Leadership \& Organization Development Journal, 38(4), 502-512, https://doi.org/10.1108/LODJ-03-2017-0070.

Weisburd, D., \& Neyroud, P. (2014). Police science: toward a new paradigm. Journal of Current Issues in Crime, Law and Law Enforcement, 7(2), 227-246.

Xiu, X., \& Payne, S. C. (2018). Predicting retention duration from organizational commitment profile transitions. Journal of Management, 44(5), 2142-2168. DOI: 10.1177/0149206316643166. 